DOI: https://doi.org/10.15688/jvolsu3.2017.3.11

UDC 658.012.56:[658.115.33:639.2/.3]

LBC 65.351.1-551

\title{
DEVELOPMENT OF THE CONCEPTION OF TECHNOLOGY INNOVATION PARK IN THE FISHERY COMPLEX OF THE REGION
}

\author{
Elena P. Karlina \\ Astrakhan State Technical University, Astrakhan, Russian Federation \\ Natalya A. Dubinina \\ Astrakhan State Technical University, Astrakhan, Russian Federation
}

\begin{abstract}
The fishery complex of Russia at the present stage is one of the priority areas of food security of the country. The study of the processes of development of fishery industry allows to make conclusions about the necessity of enhancing the development and implementation of innovative technologies in the field of fish processing and aquaculture. With regard to the fishery complex of the Astrakhan region, the authors substantiate the reasonability of creating a specialized technology innovation park, the target function of which is the development and commodification of innovative technologies in the field of fisheries through the organization of system interaction of the fish processing enterprises, subjects of commercial fisheries, scientific and educational institutions, innovative infrastructure objects and state authorities. The main provisions of the conception of creating a technological innovation park in the fishery complex of the region include the concept, target function, tasks, process model, functional organizational structure, which are being developed taking into account industry characteristics and the level of development of scientific and production potential of the fishery complex of the region.
\end{abstract}

Key words: technology innovation park, fishery complex, region, innovative technologies, commercialization of innovations.

УДК 658.012.56:[658.115.33:639.2/.3]

ББК 65.351.1-551

\section{РАЗРАБОТКА КОНЦЕПЦИИ ТЕХНИКО-ВНЕДРЕНЧЕСКОГО ПАРКА В РЫБОХОЗЯЙСТВЕННОМ КОМПЛЕКСЕ РЕГИОНА}

\author{
Елена Прокофьевна Карлина
}

Астраханский государственный технический университет, г. Астрахань, Российская Федерация

\section{Наталья Александровна Дубинина}

Аннотация. Рыбохозяйственный комплекс России на современном этапе является одним из приоритетных направлений обеспечения продовольственной безопасности страны. Исследование процессов развития рыбохозяйственного комплекса позволило сделать выводы о необходимости активизации разработки и внедрения инновационных технологий в сфере рыбопереработки и аквакультуры. Применительно к рыбохозяйственному комплексу Астраханской области обоснована целесообразность создания специализированного технико-внедренческого парка, целевой функцией которого является развитие и коммерциализация инновационных технологий в сфере рыбного хозяйства на основе организации системного взаимодействия рыбоперерабатывающих предприятий, субъектов товарного рыбоводства, научных и образовательных учреждений, объектов инновационной инфраструктуры и органов государственной власти. Основные положения концепции создания технико-внедренческого парка рыбохозяйственного комплекса региона: понятие,

(?) целевая функция, задачи, процессная модель, функциональная организационная структура разработаны с 
учетом отраслевых особенностей и уровня развития научно-производственного потенциала рыбохозяйственного комплекса региона.

Ключевые слова: технико-внедренческий парк, рыбохозяйственный комплекс, регион, инновационные технологии, коммерциализация инноваций.

\section{Введение}

Рыбохозяйственный комплекс России является стратегически значимым сектором экономики, обеспечивающим продовольственную безопасность страны, и включает такие виды деятельности, как: добыча и воспроизводство водных биоресурсов, рыбопереработка, аквакультура и др.

Современное состояние развития рыбохозяйственного комплекса России характеризуется положительной динамикой основных показателей. В 2010-2016 гг. улов рыбы составил 4,2-4,76 млн т, из которых на долю российской исключительной экономической зоны, а также Каспийского, Азовского и Черного морей приходилось $76 \%$, на зоны иностранных государств - $17 \%$, открытое море - $4 \%$ и на аквакультуру - 3 \%. Однако, по оценкам экспертов, половина добавленной стоимости, полученной при освоении общенационального ресурса, остается за пределами РФ: экспорт рыбной продукции (мороженого или с минимальной степенью обработки рыбного сырья) составляет 40 \% от общего объема производства, при этом Россия импортирует около $26 \%$ потребляемой рыбной продукции [6].

Перспективным видом деятельности рыбохозяйственного комплекса в последние десятилетия становится аквакультура, ускоренное развитие которой в мире обусловлено потерей биопродуктивности Мирового океана, выражающейся в стагнации объемов вылова гидробионтов Мирового океана в условиях избыточных мощностей флота, а также постоянного совершенствования орудий и приемов лова. В результате в мировой экономике сегодня производство продукции аквакультуры является самым быстрорастущим сегментом продовольственного рынка [5].

Темпы и масштабы развития товарного выращивания рыбы в России значительно отстают от общемировой тенденции. По данным ФАО, мировой улов рыбы за период с 2001 по 2013 г. не изменился и составил 93,8 млн т, при этом производство аквакультуры в мире увеличилось более чем в 2 раза, в России - в 1,7 раза, в общем производстве рыбной продукции в мире в 2013 г. доля аквакультуры составила 50,9 \%, в России - 3,6 \% [6].

Сложившаяся ситуация в рыбохозяйственном комплексе России сформировалась в результате влияния следующих факторов:

- высокая зависимость рыбохозяйственного комплекса от импорта зарубежных технологий переработки сырья, современного оборудования и высококачественной рыбной продукции для российских потребителей с одновременным сокращением научных исследований и низкой инновационной активностью привели к использованию отечественными компаниями морально устаревших технологий и оборудования;

- отсутствие развитого рынка рыбной продукции и функционирующей рыночной инфраструктуры, неэффективные менеджмент и логистика обусловили преобладание на рынке рыбопродукции с низкой добавленной стоимостью;

- низкая инвестиционная привлекательность отрасли, рост производственных расходов увеличивают себестоимость выпускаемой продукции, тем самым снижая ее конкурентоспособность на внутреннем и внешнем рынках [2].

Вышеизложенное позволяет выделить наиболее значимое направление эффективного развития рыбохозяйственного комплекса России - разработка и внедрение новых технологий, обеспечивающих производство конкурентоспособной продукции.

\section{Предпосылки разработки проекта технико-внедренческого парка рыбохозяйственного комплекса Астраханской области}

Рыбохозяйственный комплекс Астраханской области занимает 10-е место среди субъектов РФ по производству рыбы жи- 
вой, свежей и охлажденной и второе - среди субъектов РФ по Южному федеральному округу.

К основным направлениям деятельности рыбохозяйственного комплекса Астраханской области относятся: вылов водных биоресурсов, воспроизводство, товарное рыбоводство (аквакультура), переработка сырья, выпуск различных видов рыбной продукции, организация и проведение научных исследований, подготовка специалистов, которые осуществляются более чем 200 предприятиями и организациями различных форм собственности, при этом на долю малых предприятий приходится 80 \% объема выпуска товарной рыбной продукции [3].

Аналитическое исследование состояния рыбной отрасли региона, проведенное авторами, позволило сформулировать следующие выводы:

- прирост количественных показателей производственно-хозяйственной деятельности предприятий комплекса является результатом экстенсивного развития: увеличения квот на вылов рыбы и объемов их освоения, роста количества рыбоводных хозяйств и расширения нагульных площадей, приспосабливаемых под рыбоводство;

- отсутствие системного взаимодействия между субъектами рыбопереработки и товарного рыбоводства, низкие темпы модернизации материально-технической базы предприятий способствовали перенасыщению рынка живой и охлажденной прудовой рыбой;

- высокая себестоимость товарной рыбы, несоответствие технологического весового стандарта прудовой рыбы, направляемой на переработку (консервы, кулинария и др.), требованиям технологии переработки, ограниченный видовой состав выращиваемой рыбы в прудовых хозяйствах не позволяют производить рыбную продукцию глубокой переработки.

Решение указанных проблем возможно в результате инновационного развития рыбохозяйственного комплекса региона, основной целью которого выступает обновление материально-технической базы и совершенствование существующих технологий производства товарной рыбы, а также разработка новых технологий выращивания нетрадиционных для
Астраханской области объектов аквакультуры, что, в свою очередь, обусловливает необходимость проведения научно-исследовательских работ по технологическому обеспечению развития и интенсификации рыбоводного производства.

Таким образом, повышение эффективности рыбохозяйственного комплекса региона, его места и роли в экономике России предопределяет поиск и реализацию механизма, обеспечивающего системное взаимодействие рыбоперерабатывающих предприятий, субъектов товарного рыбоводства, научных и образовательных учреждений, объектов инновационной инфраструктуры и органов государственной власти. При этом механизм должен иметь определенное функционально-технологическое и организационное построение, адекватное целям и условиям развития рыбохозяйственного комплекса региона в целом и его отдельных секторов.

В настоящее время в Астраханской области создана инновационная инфраструктура - АУ АО «Астраханский областной инновационный центр», предметом деятельности которого является предоставление государственных услуг по созданию и развитию инфраструктуры поддержки предпринимательства - бизнес-инкубаторов, и на базе которого функционирует ряд организаций: Центр кластерного развития, Региональный центр инжиниринга для субъектов малого и среднего предпринимательства, Центр инноваций в социальной сфере. Деятельность указанных организаций в основном направлена на предоставление услуг и оказание содействия развитию бизнеса отдельных субъектов малого и среднего предпринимательства. Единственной организацией, заинтересованной в кооперации субъектов малого и среднего предпринимательства определенного вида экономической деятельности, является Центр кластерного развития, поддерживающий и способствующий развитию кластерных инициатив, в том числе и в рыбохозяйственном комплексе.

Созданный в 2013 г. территориальный кластер аквакультуры и рыбного хозяйства объединил 26 субъектов малого предпринимательства рыбной отрасли, более $90 \%$ которых - субъекты товарного рыбоводства. В рамках кластера решаются проблемы, связан- 
ные с текущей производственно-хозяйственной деятельностью предприятий кластера: формирование рыбопосадочного материала, развитие кормовой базы, интенсификация товарного рыбоводства и, частично - с разработкой и внедрением инновационных решений в технологии рыбных продуктов, основанных на использовании многофункционального технологического оборудования с универсальными возможностями ресурсосберегающего производства качественного продукта в промышленных масштабах. Стратегические перспективы развития кластера - масштабное внедрение инновационных технологий, позволяющих увеличить производство продукции аквакультуры глубокой переработки, не получили должного развития. Основными причинами сложившейся ситуации выступают: низкий уровень кооперационного взаимодействия участников кластера и недоиспользование высокого научно-исследовательского потенциала региона.

В этой связи авторами разработан проект концепции технико-внедренческого парка рыбохозяйственного комплекса, целевой функцией которого является развитие и коммерциализация инновационных технологий в сфере рыбного хозяйства на основе организации взаимодействия научных и образовательных учреждений и организаций, рыночных субъектов и органов государственной власти.

\section{Основные положения концепции технико-внедренческого парка рыбохозяйственного комплекса Астраханской области}

В российском законодательстве определение технопарка дано применительно к технопаркам высоких технологий: «форма территориальной интеграции коммерческих и некоммерческих организаций науки и образования, финансовых институтов, предприятий и предпринимателей, взаимодействующих между собой, с органами государственной власти, органами местного самоуправления, осуществляющих формирование современной технологической и организационной среды с целью инновационного предпринимательства и реализации венчурных проектов» [1].
В научной и экономической литературе понятие технопарка трактуется неоднозначно и корреспондирует с понятиями «индустриальный парк», «промышленный парк» и др. (см.: $[4 ; 7 ; 8]$ ). Применительно к целям данного исследования, технико-внедренческий парк рыбохозяйственного комплекса (ТВПРК) авторы определяют как форму территориальной интеграции научных и образовательных учреждений и организаций, субъектов рыбного хозяйства и органов государственной власти, главной целью деятельности которого является разработка и внедрение инновационных технологий и продуктов в области рыбопереработки и аквакультуры (см. рисунок).

Отличительными характеристиками ТВПРК от других субъектов инновационной инфраструктуры региона являются:

- наличие ключевой специализации ТВПРК - технологии рыбопереработки и производства товарной рыбы;

- в отличие от существующих в регионе бизнес-инкубаторов и технопарков, одной из основных функций ТВПРК является внедрение и коммерциализация разработок при непосредственном участии субъектов предпринимательства рыбной отрасли;

- базу формирования ТВПРК составляют действующие в регионе специализированные научные и образовательные учреждения и организации с высоким уровнем инновационного потенциала: ФГБОУ ВО «АГТУ» и ФГБНУ «Каспийский научно-исследовательский институт рыбного хозяйства».

Целевая функция ТВПРК предопределяет задачи его функционирования:

- разработка и внедрение инновационных технологий рыбопереработки и производства товарной рыбы;

- создание необходимых условий для производства рыбной продукции глубокой переработки, расширения видового состава выращиваемой рыбы и развития инфраструктуры рынка рыбной продукции;

- организация производства конкурентоспособной на внутреннем и внешнем рынках товарной рыбной продукции на основе кооперации субъектов рыбохозяйственного комплекса.

Проектирование структуры ТВПРК должно осуществляться не только с учетом 


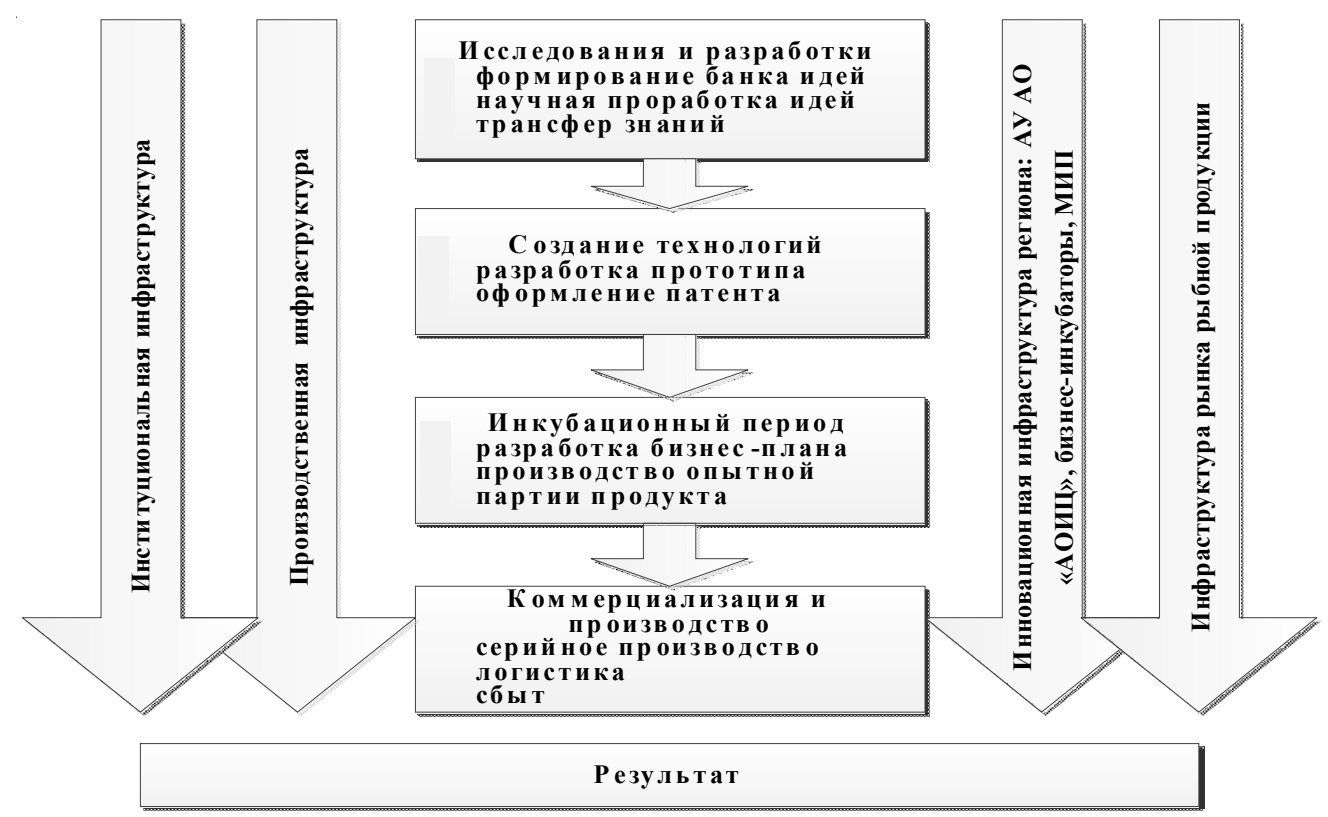

Рисунок. Процессная модель технико-внедренческого парка рыбохозяйственного комплекса региона

Примечание. Составлено авторами.

комплекса задач, позволяющим выделить функциональные структуры, но и с учетом существующего несовпадения интересов резидентов ТВПРК (субъектов рыбного хозяйства) и организаций, обеспечивающих его функционирование. Данное несовпадение обусловлено противоречивостью целеполагания: субъекты рыбного хозяйства (малые предприятия и индивидуальные предприниматели) осуществляют предпринимательскую деятельность с целью получения прибыли, одним из факторов увеличения которой является снижение затрат. В то же время разработка и коммерциализация инновационных технологий предполагает использование значительных инвестиционных ресурсов.

В этой связи формирование структуры ТВПРК на базе имеющегося научно-производственного потенциала рыбохозяйственного комплекса региона (инновационно-технологический центр ФГБОУ ВО «АГТУ», ФГБНУ «Каспийский научно-исследовательский институт рыбного хозяйства» - подведомственные организации Федерального агентства по рыболовству) и малых инновационных предприятий в сфере рыбопереработки и аквакультуры позволит минимизировать текущие затраты и стоимость привлекаемых инвестиционных ресурсов.
Проектируемая функциональная организационная структура ТВПРК представлена в таблице.

В качестве резидентов ТВПРК определены субъекты предпринимательства рыбохозяйственного комплекса: малые и средние предприятия, индивидуальные предприниматели в сфере рыбопереработки и товарного рыбоводства, инфраструктурного обеспечения рынка рыбной продукции.

\section{Заключение}

Аналитическое исследование современного уровня развития рыбохозяйственного комплекса России в целом и Астраханской области - в частности выявило ряд проблем, оказывающих негативное влияние на эффективность его деятельности: сырьевое экспортно-ориентированное производство рыбной продукции, высокая технологическая и продуктовая импортозависимость, преобладание в структуре производства рыбопродукции с низкой добавленной стоимостью, что позволило сформулировать вывод о необходимости активизации инновационной деятельности посредством создания региональных специализированных технопарков. Сформулированные базовые положения концепции создания технико-внедренческого парка рыбохозяйственного комплекса Астраханской области 
Функциональная организационная структура ТВПРК Астраханской области

\begin{tabular}{|c|c|c|}
\hline $\begin{array}{c}\text { Структура } \\
\text { ТВПРК }\end{array}$ & Вид деятельности & Функциональные подразделения \\
\hline $\begin{array}{l}\text { Инновационно- } \\
\text { технологиче- } \\
\text { ский центр }\end{array}$ & $\begin{array}{l}\text { - Организация и проведе- } \\
\text { ние НИОКР: формирова- } \\
\text { ние банка идей, трансфер } \\
\text { знаний; } \\
\text { - создание технологий; } \\
\text { - проведение лаборатор- } \\
\text { ных исследований и экс- } \\
\text { периментов }\end{array}$ & $\begin{array}{l}\text { - Инновационно-технологический центр аквакультуры и вод- } \\
\text { ных биоресурсов ФГБОУ ВО «АГТУ»: лаборатории «Осетро- } \\
\text { водство и перспективные объекты аквакультуры», «Криотехно- } \\
\text { логии в аквакультуре», «Физиология и питание рыб», «Аква- } \\
\text { биотехнопарк»; научно-исследовательская лаборатория океа- } \\
\text { нологии, гидрологии и водных ресурсов Института водных } \\
\text { проблем РАН. } \\
\text { - Инновационно-исследовательская лаборатория «Пищевая } \\
\text { биотехнология и биологически активные вещества». } \\
\text { - МИП «ИНТЕГРИ-А Текнолоджи» ФГБНУ «Каспийский на- } \\
\text { учно-исследовательский институт рыбного хозяйства» }\end{array}$ \\
\hline $\begin{array}{l}\text { Сервисный } \\
\text { центр }\end{array}$ & $\begin{array}{l}\text { - Оказание информацион- } \\
\text { ных, консалтинговых, ин- } \\
\text { жиниринговых, маркетин- } \\
\text { говых услуг; } \\
\text { - оказание юридических, } \\
\text { бухгалтерских, посредни- } \\
\text { ческих услуг }\end{array}$ & $\begin{array}{l}\text { - Рекламно-информационный центр. } \\
\text { - Пресс-центр АГТУ. } \\
\text { - Сервисный отдел. } \\
\text { - Отдел трансфера технологий. } \\
\text { - Сектор фандрайзинга и молодежной науки. } \\
\text { - Отдел маркетинга. } \\
\text { - Международный отдел. } \\
\text { - Издательство АГТУ. } \\
\text { - Юридический отдел ФГБНУ «Каспийский научно-исследо- } \\
\text { вательский институт рыбного хозяйства» }\end{array}$ \\
\hline Учебны & $\begin{array}{l}\text { - Организация и оказание } \\
\text { образовательных услуг } \\
\text { совместно с компаниями- } \\
\text { резидентами; } \\
\text { - экспозиция достижений } \\
\text { НТП }\end{array}$ & $\begin{array}{l}\text { - Институт рыбного хозяйства, биологии и природопользова- } \\
\text { ния АГТУ. } \\
\text { - Волго-каспийский морской рыбопромышленный колледж. } \\
\text { - Дмитровский рыбохозяйственный технологический институт. } \\
\text { - Институт дополнительного профессионального образования. } \\
\text { - Научно-образовательный центр микробиологии, биотехноло- } \\
\text { гии и ветеринарно-санитарной экспертизы }\end{array}$ \\
\hline $\begin{array}{l}\text { Демонстраци- } \\
\text { онно-испыта- } \\
\text { тельный центр }\end{array}$ & $\begin{array}{l}\text { - Предоставление воз- } \\
\text { можностей для размеще- } \\
\text { ния оборудования компа- } \\
\text { ниями-производителями, в } \\
\text { целях демонстрации; } \\
\text { - организация доступа к } \\
\text { оборудованию в учебных } \\
\text { целях; } \\
\text { - проведение демонстра- } \\
\text { ций и испытаний обору- } \\
\text { дования в рабочем режиме }\end{array}$ & $\begin{array}{l}\text { - Научно-экспериментальная база «БИОС» ФГБНУ «Касп- } \\
\text { НИРХ». } \\
\text { - Инновационный центр «Биоаквапарк - Научно-технический } \\
\text { центр аквакультуры». } \\
\text { - Центр коллективного пользования «Биохимический и эколо- } \\
\text { гический мониторинг». } \\
\text { - Центр транспортной логистики. } \\
\text { - Научно-исследовательский и внедренческий центр приклад- } \\
\text { ной биотехнологии. } \\
\text { - Научно-исследовательская лаборатория «Ресурсосберегаю- } \\
\text { щие технологии и природообустройство». } \\
\text { - Испытательный центр «Маrine Tесhnology Service» }\end{array}$ \\
\hline
\end{tabular}

Примечание. Составлено авторами.

определяют целевую функцию, задачи и функциональную структуру технопарка с учетом специфики отраслевой деятельности и существующего научно-производственного потенциала региона и являются основой для разработки комплекса практических мероприятий по реализации проекта ТВПРК региона.

\section{СПИСОК ЛИТЕРАТУРЫ}

1. Государственная программа «Создание в Российской Федерации технопарков в сфере высо- ких технологий» : одобрена Распоряжением Правительства РФ от 10.03.2006 № 328-р (ред. от 27.12.2010) // Собрание законодательства Российской Федерации (СЗРФ). - 2006. - № 11. - Ст. 1226.

2. Дубинина, Н. А. Потенциал развития рыбного хозяйства в России: аналитический аспект / Н. А. Дубинина, Е. П. Карлина // Вестник Астраханского государственного технического университета. Серия: Экономика. - 2017. - № 3. - С. 79-88. DOI: 10.24143/2073-5537-2017-3-79-88.

3. Карлина, Е. П. Социально-экономическое развитие региона: теория и практика / Е. П. Карлина, Т. Н. Максимова. - Астрахань : ГУПИПК, 2003. -108 с. 
4. Козлова, В. Н. Типы особых экономических зон и их соотношение с парковыми территориями развития / В. Н. Козлова. - Электрон. текстовые дан. - Режим доступа: http://www.gramota.net/ materials/3/2015/1-2/20.html. - Загл. с экрана.

5. Прогноз научно-технологического развития агропромышленного комплекса Российской Федерации на период до 2030 года / Минсельхоз России ; Нац. исслед. ун-т «Высшая школа экономики». - М. : НИУ ВШЭ, 2017. - 140 с.

6. Проект доклада рабочей группы Президиума государственного совета «О развитии рыбохозяйственного комплекса Российской Федерации». Москва, 2015. - Электрон. текстовые дан. - Режим доступа: http://www.vniro.ru/files/Gossovet_doklad. pdf. - Загл. с экрана.

7. Терещенко, Л. К. О правовом статусе технопарков / Л. К. Терещенко, А. В. Калмыкова // Журнал российского права. - 2011. - № 12. - С. 21-30.

8. Трибушная, В. Х. Инновационная инфраструктура как необходимость поддержки наукоемкого предпринимательства: технопарки и стратегическое управление : монография / В. Х. Трибушная. - Ижевск : Изд-во Удмурт. гос. ун-та, 2011. $240 \mathrm{c}$.

\section{REFERENCES}

1. Gosudarstvennaya programma «Sozdanie v Rossiyskoy Federatsii tekhnoparkov v sfere vysokikh tekhnologiy»: odobrena Rasporyazheniem Pravitelstva RF ot 10.03.2006 № 328-r (red. ot 27.12.2010) [State Program "Creation of Technoparks in the Russian Federation in the Sphere of High Technologies": Approved by the Decree of the Government of the Russian Federation on March 10, 2006 no. 328-r (amend. of December 27, 2010)]. Sobranie zakonodatelstva Rossiyskoy Federatsii, 2006, no. 11, art. 1226.

2. Dubinina N.A., Karlina E.P. Potentsial razvitiya rybnogo khozyaystva $\mathrm{v}$ Rossii: analiticheskiy aspekt [The Potential of Fisheries Development in Russia: Analytical Aspect]. Vestnik Astrakhanskogo gosudarstvennogo tekhnicheskogo universiteta. Seriya: Ekonomika [Vestnik of Astrakhan State Technical University. Series: Economics], 2017, no. 3, pp. 79-88. DOI: 10.24143/2073-5537-2017-3-79-88.

3. Karlina E.P., Maksimova T.N. Sotsialnoekonomicheskoe razvitie regiona: teoriya i praktika [The Socio-Economic Development of the Region: Theory and Practice]. Astrakhan, GUP IPK, 2003. $108 \mathrm{p}$.

4. Kozlova V.N. Tipy osobykh ekonomicheskikh zon $i$ ikh sootnoshenie s parkovymi territoriyami razvitiya [Types of Special Economic Zones and Their Relation with the Park Areas of the Development]. URL: http://www.gramota.net/materials/3/2015/1-2/20.html.

5. Prognoz nauchno-tekhnologicheskogo razvitiya agropromyshlennogo kompleksa Rossiyskoy Federatsii na period do 2030 goda [Forecast of scientific and technological development of the agroindustrial complex of the Russian Federation for the period till2030]. Minselkhoz Rossii; Nats. issled. un-t "Vysshaya shkola ekonomiki»[The Ministry of Agriculture; National Research University "Higher school of Economics"]. Moscow, NIU VShE Publ., 2017. 140 p.

6. Proekt doklada rabochey gruppy Prezidiuma gosudarstvennogo soveta «O razvitii rybokhozyaystvennogo kompleksa Rossiyskoy Federatsii». Moskva, 2015 [The Draft Report of the Working Group of Presidium of the State Council "On the Development of the Fisheries Complex of the Russian Federation". Moscow, 2015]. URL: http:// www.vniro.ru/files/Gossovet_doklad.pdf.

7. Tereshchenko L. K., Kalmykova A.V. O pravovom statuse tekhnoparkov [On the Legal Status of Technoparks]. Zhurnal rossiyskogo prava, 2011, no. 12, pp. 21-30.

8. Tribushnaya V.Kh. Innovatsionnaya infrastruktura kak neobkhodimost podderzhki naukoemkogo predprinimatelstva: tekhnoparki $i$ strategicheskoe upravlenie: monografiya [Innovative Infrastructure as the Need to Support KnowledgeIntensive Entrepreneurship: Technology Parks and Strategic Management]. Izhevsk, Izd-vo Udmurt. gos. un-ta, 2011. 240 p.

\section{Information about the Authors}

Elena P. Karlina, Doctor of Sciences (Economics), Professor, Department of Industrial Management, Astrakhan State Technical University, Tatishcheva St., 16, 414056 Astrakhan, Russian Federation, e_karlina@list.ru.

Natalya A. Dubinina, Candidate of Sciences (Economics), Professor, Department of Industrial Management, Astrakhan State Technical University, Tatishcheva St., 16, 414056 Astrakhan, Russian Federation, dubinina-nat@rambler.ru. 


\section{МАКРОЭКОНОМИЧЕСКИЕ И ИНСТИТУЦИОНАЛЬНЫЕ УСЛОВИЯ}

\section{Информация об авторах}

Елена Прокофьевна Карлина, доктор экономических наук, профессор кафедры производственного менеджмента, Астраханский государственный технический университет, ул. Татищева, 16, 414056 г. Астрахань, Российская Федерация, e_karlina@list.ru.

Наталья Александровна Дубинина, кандидат экономических наук, профессор кафедры производственного менеджмента, Астраханский государственный технический университет, ул. Татищева, 16, 414056 г. Астрахань, Российская Федерация, dubinina-nat@rambler.ru. 